\title{
Why do people with chronic disease not contact consumer health organisations? A survey of general practice patients
}

\author{
Frances M. Boyle, Julie H. Dean, Charlotte E. Young and Allyson J. Mutch \\ School of Public Health, The University of Queensland, Herston, QLD, Australia
}

\begin{abstract}
Aim: Consumer health organisations (CHOs) are non-profit or voluntary sector organisations that promote and represent the interests of patients and carers affected by particular conditions. The purpose of this study was to examine, among patients with chronic disease, what differentiates those who contact $\mathrm{CHO}$ s from those who do not and what stops people from making contact. Background: $\mathrm{CHOs}$ can enhance people's capacity to manage chronic disease by providing information, education and psychosocial support, but are under-utilised. Little is known about barriers to access. Methods: Data were from a baseline telephone survey conducted as part of a randomised trial of an intervention to improve access to $\mathrm{CHOs}$. Participants constituted a consecutive sample of 276 adults with diagnosed chronic disease recruited via 18 general practitioners in Brisbane, Australia. Quantitative survey items examined participants' use and perceptions of $\mathrm{CHOs}$ and a single open-ended question explored barriers to $\mathrm{CHO}$ use. Multiple logistic regression and thematic analysis were used. Findings: Overall, $39 \%$ of participants had ever contacted a $\mathrm{CHO}$ for their health and $28 \%$ had contacted a $\mathrm{CHO}$ specifically focussed on their diagnosed chronic condition. Diabetes, poorer self-reported physical health and greater health system contact were significantly associated with $\mathrm{CHO}$ contact. The view that 'my doctor does it all' was prevalent and, together with a belief that their health problems were 'not serious enough', was the primary reason patients did not make contact. Conclusion: Attitudinal and system-related barriers limit use of $\mathrm{CHOs}$ by those for whom they are designed. Developing referral pathways to $\mathrm{CHO}$ and promoting awareness about what they offer is needed to improve access.
\end{abstract}

Key words: chronic disease; consumer health organisations; primary care; selfmanagement; voluntary groups

Received 1 May 2015; revised 7 August 2015; accepted 13 October 2015; first published online 17 November 2015

\section{Introduction}

The concept of chronic disease self-management has been embraced by health systems in countries throughout the world in an effort to stem the human and health systems costs associated with the rising prevalence of long-term chronic conditions (Epping Jordan et al., 2004). Chronic disease care requires health professionals and patients to

Correspondence to: Frances M. Boyle, School of Public Health, The University of Queensland, Public Health Building, Herston Road, Herston, QLD 4006, Australia. Email: f.boyle@uq.edu.au adapt their approaches to manage the ongoing demands of these conditions and limit their progression. Increasingly, general practitioners (GPs) are expected to work with patients to develop care plans, lead multidisciplinary teams and help their patients learn self-management skills (Bodenheimer et al., 2002; Oldroyd et al., 2003; Department of Health and Ageing, Commonwealth Government of Australia, 2013; Eaton et al., 2015). People who engage in self-management have better health outcomes including improved self-care, enhanced health status and more efficient health services use (Bodenheimer et al., 2002; 
Eaton et al., 2015). Educating and supporting patients in self-management presents challenges for GPs who face competing time and resource demands (Bodenheimer et al., 2002; Oldroyd et al., 2003; Department of Health and Ageing, Commonwealth Government of Australia, 2013; Eaton et al., 2015). Accordingly, patients may not receive the selfmanagement support needed to adapt successfully to chronic conditions requiring behavioural change and psychosocial adjustment. Meeting patients' diverse needs and fostering self-management requires a mix of clinical and non-clinical resources (Fisher et al., 2014; Morris et al., 2015).

Consumer health organisations (CHOs) have long been a part of the health care landscape (Baggott and Jones, 2014). These non-profit or voluntary sector organisations promote and represent the interests of patients and carers affected by particular conditions. The provision of information, care and support to those experiencing a particular condition is the leading priority for most CHOs, but the scope of activities is often much broader, including awareness raising and involvement in research, policy, health promotion and prevention (Baggott and Jones, 2014). As an existing resource offering flexible and low-cost services that can extend, reinforce and complement clinical care for people with chronic disease, CHOs constitute part of a wider system of selfmanagement support (Morris et al., 2015).

Kurtz (1997) identifies five basic processes that typify CHOs: giving support; imparting information; conveying a sense of belonging; communicating experiential knowledge and teaching coping methods. CHOs provide unique opportunities for peer support by linking people with similar conditions and enabling sharing of personal knowledge and experiences (Fisher et al., 2014). Their non-clinical focus also enables flexible and ongoing support that is integrated into people's everyday lives and promotes broader well-being (Morris et al., 2015). CHOs are well placed to meet the varied support needs and preferences of patients through a range of support options including printed information, newsletters, links to other resources, telephone and online support and information, and educational activities. Engagement with CHOs may be active (eg, attendance at group meetings) or 'at a distance' (eg, use of written materials or social media) and ongoing, occasional or one-off.

Primary Health Care Research \& Development 2016; 17: 393-404
Evidence of outcomes following contact with $\mathrm{CHOs}$, although scarce, is encouraging. A review of 45 studies of the effectiveness of CHOs in supporting people across diverse range of conditions showed improvements in knowledge, mastery, coping, control and psychosocial wellbeing (Kyrouz et al., 2002). Quantitative and qualitative explorations of specific CHOs suggest high levels of satisfaction and emotional, informational and practical support benefits for users (Beesley et al., 2009; Boyle et al., 2009; Sav et al., 2014). Recent reviews highlight the contributions of peer support to health-related outcomes (Fisher et al., 2014) and the benefits of facilitating access to voluntary and community services for primary care patients with psychosocial problems (Mossabir et al., 2015). Two randomised controlled trials (Grant et al., 2000; Blakeman et al., 2014), both in the United Kingdom, demonstrate modest health improvements for general practice patients actively linked to community resources.

Yet, CHOs remain a relatively untapped health system resource. A UK survey of 2157 adults with a chronic disease found only $5 \%$ had ever contacted a CHO (Ellins and Coulter, 2005), whereas a Canadian survey of 267 patients with diabetes found between 3 and $13 \%$ had used a diabetes support organisation (Gucciardi et al., 2006). Low uptake is characteristic of many community-based health interventions and a limitation of chronic disease self-management programs. Cost, transport, limited mobility, poor literacy, time constraints, limited or inaccurate information, and lack of encouragement to make contact have been implicated as access barriers (Graziani et al., 1999; Jordan et al., 2008; Mahomed et al., 2008). Recommendation or endorsement by a doctor influences whether people use services (Graziani et al., 1999; Jordan et al., 2008; Mahomed et al., 2008; Beesley et al., 2009; Boyle et al., 2009; Sav et al., 2014). Few studies of access to CHOs are available but one Australian qualitative study of 97 people with chronic disease (Sav et al., 2014) identified lack of referral pathways from general practice as a prominent barrier.

Greater understanding of users and non-users of CHOs is needed to identify the nature of barriers that exist and whether these might be addressed to improve the reach of organisations. Data collected by telephone survey in the baseline phase of a randomised controlled trial of an intervention to 
improve $\mathrm{CHO}$ access (Boyle et al., 2011) provided a unique opportunity to investigate this issue in a community-based sample of general practice patients with diagnosed chronic disease. This study reports on (i) What differentiates those who contact CHOs from those who do not? and (ii) What stops people from making contact?

\section{Methods}

\section{Study design and setting}

The source of data was the baseline phase of a randomised controlled trial designed to evaluate whether a print-based information package increased $\mathrm{CHO}$ use among general practice patients with diagnosed chronic disease. The consecutive sample of 276 trial participants was recruited by 18 GPs from 11 different practices in Brisbane, Australia. Participation involved completion of a telephone survey, random allocation to receive the information package or standard care, and completion of a follow-up telephone survey approximately four months after the first. Full details of the trial are provided elsewhere (Boyle et al., 2011). The data presented in this study were collected in the first telephone survey, which used a questionnaire containing quantitative measures to assess views and characteristics associated with $\mathrm{CHO}$ contact and a single open-ended question to explore barriers to $\mathrm{CHO}$ contact. Participants completed a computer-assisted telephone interview (CATI) within two weeks of recruitment and before being randomised to an intervention or usual care group. The CATI method is a well-established data collection technique enabling trained interviewers to administer a pre-programmed questionnaire by telephone. Responses are automatically entered and coded during the interview enhancing the timeliness and quality of data (De Vaus, 2002). Up to 10 call-backs were made to maximise response rates. Interviews took 10-20 min. The study was approved by The University of Queensland's Behavioural and Social Sciences Ethical Review Committee.

\section{Participants}

Participant recruitment involved a two-stage process: the recruitment of GPs, followed by the recruitment of patients with diagnosed chronic disease. A random sample of 200 GPs was invited by mail to participate in the study but only eight GPs were recruited in this way. Chain referral, or snowball sampling, where respondents are asked to refer the researcher to one or more members of the target group was used to enlist further GPs. During a specified recruitment period of up to three weeks, participating GPs asked consecutive eligible patients if they would agree to join the study. Eligibility criteria were age 18 years and over; sufficient English language skills to complete a telephone interview; and a diagnosis of diabetes, arthritis, osteoporosis, ankylosing spondylitis, asthma, chronic hepatitis, haemochromatosis or renal disease based on standard diagnostic criteria. These conditions were selected because they are prevalent and contribute to a large proportion of the burden of morbidity in Australia (Australian Institute of Health and Welfare (AIHW), 2014) and had active CHOs in the study catchment area.

\section{Measures}

$\mathrm{CHO}$ contact was the primary outcome variable. All participants were asked: 'Have you ever contacted a community health organisation?' and 'Have you ever contacted [a CHO relevant to their main diagnosed chronic condition]?'. The following short definition of CHOs was read to all respondents: 'By consumer health organisations, we mean organisations, associations or support groups that provide information or other forms of support to people with particular health conditions'. The names of several local CHOs were read out and respondents were asked to indicate if they had ever contacted any of these or any other similar organisations. Those who had were asked to name the organisation(s). Two members of the research team subsequently checked the responses and any that did not meet the definition (eg, hospital clinic) were removed. All participants were asked whether their GP had ever told them about any such organisations.

To explore perceptions of CHOs and barriers to contact, participants were read a list of reasons why people might not choose to contact a $\mathrm{CHO}$ (the question was worded to be suitable for all participants regardless of whether they had 
made contact) and asked to respond using a fivepoint scale ('strongly agree' to 'strongly disagree'). The items were devised specifically for the study with reference to relevant literature. Participants who had never contacted a $\mathrm{CHO}$ were also asked a single open-ended question: 'Overall, what would you say is the main reason you have not contacted a consumer health organisation?'. Responses were entered as close to verbatim as possible.

Sociodemographic information including age, sex, ethnicity, marital status, education and workforce participation was collected.

Health service utilisation was assessed by summing the number of self-reported GP and specialist consultations, hospital, and accident and emergency attendances in the last three months.

Physical and mental health were assessed using the SF-12 Version 2 (Ware et al., 2005), a widely used measure with well-established psychometric properties across a range of conditions (Busija et al., 2011). A physical and mental component summary score is generated for each respondent. Scores $>50$ indicate above average health.

\section{Data analysis}

Quantitative data were analysed using SPSS 15.0 (SPSS, 2006). The statistical significance of associations between a range of variables and whether or not participants had ever contacted a $\mathrm{CHO}$ was assessed using $\chi^{2}$ tests (for categorical variables) and $t$-tests (for continuous variables). The 0.05 level of probability was applied and all variables that were significantly associated with $\mathrm{CHO}$ contact were included in a multiple logistic regression analysis to assess the independent contribution of each of those variables.

Thematic analysis was used to identify relevant and important themes based on responses to the open-ended question asking participants to nominate the main reason for not contacting a $\mathrm{CHO}$. Following guidelines proposed by Braun and Clarke (2006), responses were read multiple times by a member of the research team who generated initial codes to identify ideas contained in the data and subsequently grouped these into categories and themes. Independent coding of a subset of responses was undertaken by a second research team member, with any differences resolved through discussion among all research team members.

\section{Results}

\section{Sample characteristics}

In total, 374 eligible patients were invited by 18 GPs to join the study, and $276(73.8 \%)$ completed the interview (Figure 1). Completers did not differ significantly from eligible non-completers in terms of sex, age or main chronic condition (nominated and recorded by the recruiting GP). The majority of study participants were women $(66 \%)$, married or living with a partner $(57 \%)$, with an average age of 63.9 years $(\mathrm{SD}=14.70$, median $=65.0)$ and at least some secondary-level education (83\%). Most were Australian-born (78\%) and a small minority $(10 \%)$ spoke a language other than English at home. Four participants $(1.4 \%)$ identified as Aboriginal or Torres Strait Islander. Slightly more than half the participants (54\%) had some form of private health insurance. The majority were retired $(59 \%)$, with only $24 \%$ in the paid workforce. Musculoskeletal conditions (arthritis, osteoporosis and ankylosing spondylitis) were the main diagnosed chronic conditions for $52 \%$ of the 276 participants, followed by diabetes $(23 \%)$ and asthma (15\%) and smaller numbers with kidney disease $(6 \%)$, chronic hepatitis $(2 \%)$ and haemochromatosis $(2 \%)$.

\section{What differentiates those who have contacted a CHO from those who have not?}

Just over one-third of participants (38.8\%; 107 of 276) reported ever having contacted a CHO for their health and $27.5 \%$ (76 of 276) had contacted a $\mathrm{CHO}$ specifically focussed on their main diagnosed chronic condition. Those who had ever contacted a $\mathrm{CHO}$ differed significantly from those who had not (Table 1).

Patients who had been told about the organisation by a GP were significantly more likely to make contact than those who had not (52 versus $35 \%$ ), whereas those with a main diagnosis of diabetes were far more likely to have contacted a $\mathrm{CHO}$ than those with other conditions (84 versus 25\%). Participants who reported six or more GP, specialist or hospital visits in the preceding three months were more likely to have made contact (50 compared with $31-37 \%$ of those who had 


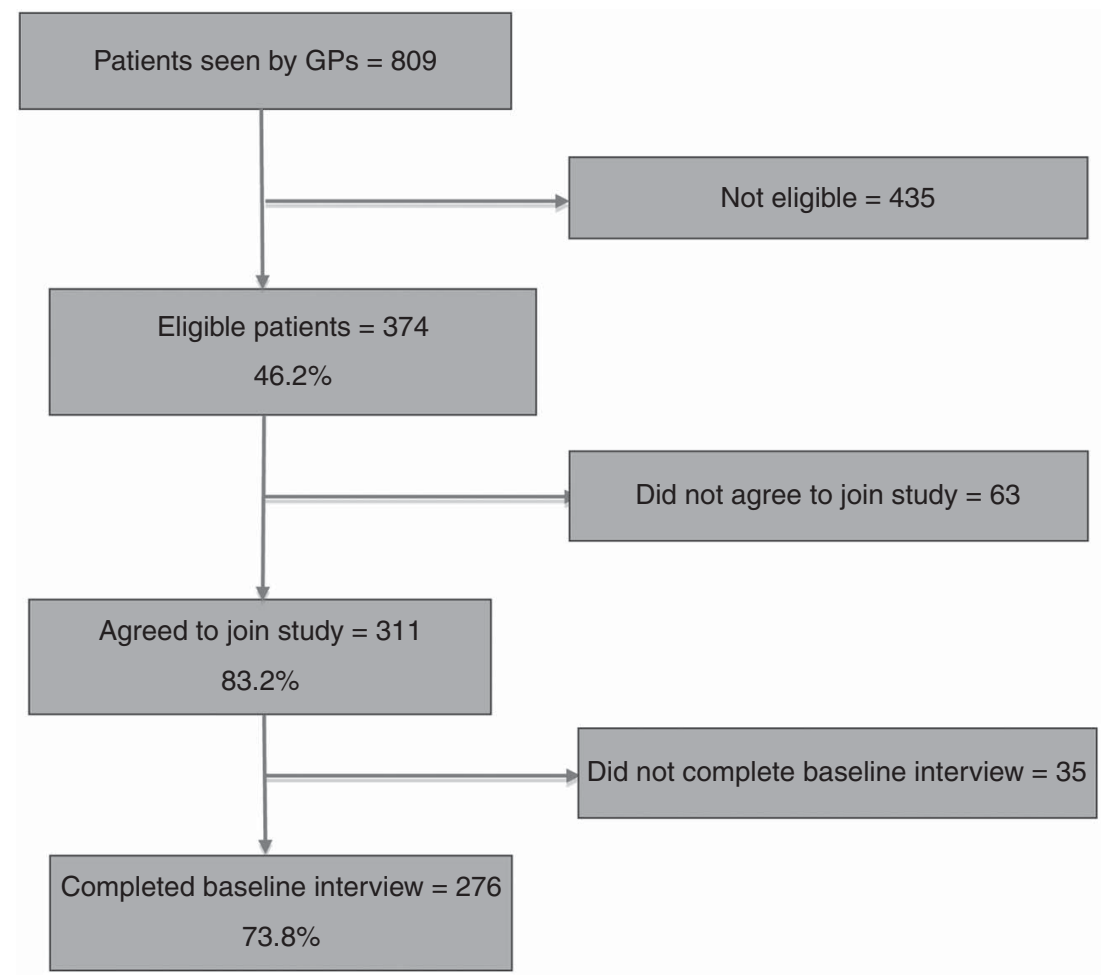

Figure 1 Participant flow and response rate. GP = general practitioner.

less health service use). Participant with poorer self-reported physical health scores more likely to have made $\mathrm{CHO}$ contact: 43 compared with $26 \%$ of those who reported better health.

Multivariate analysis showed high levels of health service use, poorer self-reported health and a main diagnosis of diabetes remained statistically significant and made independent contributions to $\mathrm{CHO}$ contact after adjusting for other variables in the model (Table 2). Greater health service use and poorer health status were each associated with an almost three-fold higher likelihood of having ever contacted a CHO [adjusted odds ratio (AOR) 2.9, 95\% confidence interval (CI) $1.3-6.1, P=0.01$ and AOR 2.8, 95\% CI 1.2$6.4, P=0.01$, respectively]. Those with diabetes were a striking 27 times more likely (AOR 26.9, 95\% CI 10.9-66.6, $P<0.001)$ irrespective of the other variables in the model. Classification tables were used to assess goodness of fit. Overall, the logistic regression model correctly classified $77 \%$ of cases.

\section{Participants' views on barriers to CHO contact}

Participants were presented with a series of statements to elicit their views on barriers to $\mathrm{CHO}$ contact (Table 3). By far the most commonly endorsed reason (agreed or strongly agreed) for not contacting a $\mathrm{CHO}$ was that the doctor gave all the care and information needed. Those who had never contacted a $\mathrm{CHO}$ were significantly more likely to hold this view (90 versus $82 \%$, $P<0.04)$ and were also significantly more likely to indicate their health problems were not serious enough (63 versus $44 \%, P<0.002)$. Lack of knowledge about what $\mathrm{CHOs}$ offered $(66 \%)$ or the organisations that existed $(53 \%)$ were relatively common barriers for all participants, whereas slightly fewer cited lack of time $(44 \%)$, cost $(43 \%)$, difficulty getting to $\mathrm{CHO}$ activities $(43 \%)$ and not feeling well enough $(33 \%)$ as barriers. Group processes were also identified as barriers, including concern regarding pressure to get involved (45\%), feeling burdened by others' problems $(33 \%)$, not 
Table 1 Characteristics of the 276 study participants and bivariate associations with $\mathrm{CHO}$ contact

\begin{tabular}{|c|c|c|c|c|}
\hline Variables & $n$ & $\begin{array}{l}\text { Ever contacted } \mathrm{CHO} \\
(n=107)[n(\%)]\end{array}$ & $\begin{array}{l}\text { Never contacted } \mathrm{CHO} \\
(n=169)[n(\%)]\end{array}$ & $P$-value ${ }^{a}$ \\
\hline Age (mean years) & 276 & 63.93 & 63.86 & 0.97 \\
\hline Sex & & & & 0.63 \\
\hline Male & 95 & $35(36.8)$ & $60(63.2)$ & \\
\hline Female & 181 & $72(39.8)$ & $109(60.2)$ & \\
\hline Education $^{\mathrm{b}}$ & & & & 0.64 \\
\hline No qualification & 48 & $18(37.5)$ & $30(62.5)$ & \\
\hline Secondary & 116 & $45(38.8)$ & 71 (61.2) & \\
\hline Certificate & 71 & $25(35.2)$ & $46(64.8)$ & \\
\hline Degree/diploma or higher & 40 & $19(47.5)$ & $21(52.5)$ & \\
\hline Marital status & & & & 0.24 \\
\hline Married or living with partner & 158 & $66(41.8)$ & $92(58.2)$ & \\
\hline Other & 118 & $41(34.7)$ & 77 (65.3) & \\
\hline Private health insurance & & & & 0.30 \\
\hline Yes & 150 & $54(36.0)$ & $96(64.0)$ & \\
\hline No & 126 & $53(42.1)$ & $73(57.9)$ & \\
\hline Employed in paid workforce & & & & 0.86 \\
\hline Yes & 66 & $25(37.9)$ & $41(62.1)$ & \\
\hline No & 210 & $82(39.0)$ & $128(61.0)$ & \\
\hline $\mathrm{GP}$ told about $\mathrm{CHO}^{\mathrm{c}}$ & & & & 0.02 \\
\hline Yes & 64 & $33(51.6)$ & $31(48.4)$ & \\
\hline No & 210 & $73(34.8)$ & $137(65.2)$ & \\
\hline Main condition & & & & $<0.001$ \\
\hline Diabetes & 64 & $54(84.4)$ & $10(15.6)$ & \\
\hline Other & 212 & $53(25.0)$ & $159(75.0)$ & \\
\hline Health service usage (last 3 months) & & & & 0.03 \\
\hline $1-2$ visits & 99 & $31(31.3)$ & $68(68.7)$ & \\
\hline $3-5$ visits & 95 & $35(36.8)$ & $60(63.2)$ & \\
\hline 6 or more visits & 82 & $41(50.0)$ & $41(50.0)$ & \\
\hline SF-12 - physical health & & & & 0.02 \\
\hline Average or below (score $<50)$ & 211 & $90(42.7)$ & $121(57.3)$ & \\
\hline Above average (score $50+$ ) & 65 & $17(26.2)$ & 48 (73.8) & \\
\hline SF-12 - mental health & & & & 0.99 \\
\hline Average or below (score $<50$ ) & 103 & $40(38.8)$ & $63(61.2)$ & \\
\hline Above average (score $50+$ ) & 173 & $67(38.7)$ & $106(61.3)$ & \\
\hline
\end{tabular}

$\mathrm{CHO}=$ consumer health organisation; $\mathrm{GP}=$ general practitioner. Bold values are statistically significant.

${ }^{a} \chi^{2}$ test for all variables except for age, where a $t$-test was used.

${ }^{\mathrm{b}}$ Missing data for one participant.

${ }^{\mathrm{c}}$ Missing data for two participants.

wanting to be part of a group (36\%) and being put-off by what others had said $(15 \%)$.

\section{What stopped participants from contacting a CHO?}

The purpose of the single open-ended item was to expand and contextualise the quantitative results concerning barriers to $\mathrm{CHO}$ use. The 169 participants who had never contacted a $\mathrm{CHO}$ provided a total of 234 responses (some responses contained more than one distinct reason for non-contact). Analysis of responses identified three main themes that represented the vast majority of comments

Primary Health Care Research \& Development 2016; 17: 393-404 made. These were reliance on the doctor; not sick enough or no need; and difficulties reaching the organisation. Following review of all responses, illustrative quotes were selected to capture the breadth of each theme across different chronic conditions (Table 4).

\section{Reliance on the doctor}

Approximately $20 \%$ of comments from those who had never contacted a $\mathrm{CHO}$ reinforced the view strongly expressed in the quantitative results that the doctor provided all needed care and information. Participants were generally satisfied 
Table 2 Multiple logistic model for $\mathrm{CHO}$ contact

\begin{tabular}{|c|c|c|c|c|}
\hline Variables & $n$ & Crude OR (95\% Cl) & Adjusted OR $(95 \% \mathrm{Cl})$ & Adjusted $P$-value \\
\hline \multicolumn{5}{|l|}{ Health service usage (last 3 months) } \\
\hline $1-2$ visits & 99 & 1.0 & 1.0 & \\
\hline $3-5$ visits & 95 & $1.3(0.7-2.3)$ & $1.2(0.6-2.5)$ & \\
\hline 6 or more visits & 82 & $2.2(1.2-4.0)$ & $2.9(1.3-6.1)$ & 0.01 \\
\hline \multicolumn{5}{|l|}{ SF-12 - physical health } \\
\hline Above average (score $50+$ ) & 65 & 1.0 & 1.0 & \\
\hline Average or below (score $<50$ ) & 211 & $2.1(1.1-3.9)$ & $2.8(1.2-6.4)$ & 0.01 \\
\hline \multicolumn{5}{|l|}{ Main condition } \\
\hline Other & 212 & 1.0 & 1.0 & \\
\hline Diabetes & 64 & $16.2(7.7-34.1)$ & $26.9(10.9-66.6)$ & $<0.001$ \\
\hline \multicolumn{5}{|l|}{ Told by GP about $\mathrm{CHO}^{\mathrm{a}}$} \\
\hline No & 210 & 1.0 & 1.0 & \\
\hline Yes & 64 & $2.0(1.1-3.5)$ & $1.6(0.7-3.4)$ & 0.28 \\
\hline
\end{tabular}

$\mathrm{CHO}=$ consumer health organisation; $\mathrm{OR}=$ odds ratio; $\mathrm{Cl}=$ confidence interval; $\mathrm{GP}=$ general practitioner .

${ }^{a}$ Missing data for two participants.

Table 3 Reasons for not contacting a CHO, showing percentage of study participants who agreed/strongly agreed or disagreed/strongly disagreed with each statement

\begin{tabular}{|c|c|c|c|c|}
\hline Reason for not contacting $\mathrm{CHO}$ & $\begin{array}{l}\text { Ever contacted } \\
(n=107)(\%)\end{array}$ & $\begin{array}{l}\text { Never contacted } \\
(n=169)(\%)\end{array}$ & All $(n=276)(\%)$ & $P$-value ${ }^{a}$ \\
\hline Doctor gives all needed care and information & 82.1 & 90.5 & 87.2 & 0.04 \\
\hline Don't know enough about what $\mathrm{CHOs}$ offer & 62.3 & 68.3 & 65.9 & 0.31 \\
\hline Health problems are not serious enough & 43.9 & 63.3 & 55.8 & 0.002 \\
\hline Don't know what organisations exist & 49.5 & 55.6 & 53.3 & 0.32 \\
\hline Could feel pressure to get involved & 46.7 & 44.0 & 45.1 & 0.65 \\
\hline Not enough time & 46.7 & 42.6 & 44.2 & 0.50 \\
\hline It would cost too much money & 36.4 & 47.0 & 42.9 & 0.09 \\
\hline Too hard to get to $\mathrm{CHO}$ activities & 44.9 & 41.1 & 42.5 & 0.54 \\
\hline Don't like being part of an organisation/group & 34.9 & 36.1 & 35.7 & 0.83 \\
\hline Could feel burdened with others problems & 32.7 & 33.3 & 33.1 & 0.91 \\
\hline Not enough energy/not well enough & 31.8 & 33.3 & 32.7 & 0.79 \\
\hline What others have said has put you off & 19.8 & 11.3 & 14.6 & 0.05 \\
\hline
\end{tabular}

$\mathrm{CHO}=$ consumer health organisation.

${ }^{2} \chi^{2}$ analysis.

to rely exclusively on their doctor for the management of their condition and so did not need to contact a CHO. Some commented they would seek additional services if their doctor no longer provided them with the information they required, but, more often, participants underlined the pivotal role of the doctor in facilitating $\mathrm{CHO}$ access. The strong suggestion was that initiating contact with a $\mathrm{CHO}$ would be highly unlikely without direction from the doctor.

\section{Not sick enough}

Many participants believed their health problems were 'not serious enough' to justify contacting a
$\mathrm{CHO}$ or that they had 'no need at this stage'. This emerged as the major theme with almost half of the comments reflecting this view. $\mathrm{CHOs}$ seemed to be viewed as something of a 'last resort' with participants stating they would consider making contact should their health decline in the future.

\section{Difficulties reaching the organisation}

A relatively small number of participants highlighted difficulties in reaching or engaging with an organisation for their health needs. Consistent with the quantitative data, access issues featured less prominently than the attitudinal factors just described, and were mentioned by $<10 \%$ of 
Table 4 Barriers to contacting $\mathrm{CHO}$ and illustrative quotes

\begin{tabular}{|c|c|}
\hline Barriers & Illustrative quotes \\
\hline $\begin{array}{l}\text { Reliance on the } \\
\text { doctor }\end{array}$ & $\begin{array}{l}\text { 'I don't need to, my doctor provides it all' }(0660 \text {, female with asthma aged } 42) \\
\text { 'I leave it to my doctor, I get all my care and information from her' }(0188, \text { male with arthritis } \\
\text { aged } 49) \\
\text { 'I have not been recommended by my doctor to call them. I'm still waiting' }(0475 \text {, female with } \\
\text { osteoporosis aged } 54) \\
\text { 'Doctor will tell me if I need to contact an organisation I will contact them if I need it... the doctor } \\
\text { hasn't mentioned about them at this point' }(0184, \text { male with asthma aged } 82)\end{array}$ \\
\hline $\begin{array}{l}\text { Not being sick } \\
\text { enough }\end{array}$ & $\begin{array}{l}\text { 'I never thought of it ... I suppose I don't think of myself as very sick' (0185, female with diabetes } \\
\text { aged 78) } \\
\text { 'At this stage I don't need it, I can manage myself, but if somewhere down the track I need it, then I will } \\
\text { definitely contact them' (0496, female with asthma aged } 58) \\
\text { 'Unless there's something seriously wrong with me, I won't go' (0564, female with osteoporosis } \\
\text { aged } 73) \\
\text { 'I'm not bad enough at this point' }(0212 \text {, female with arthritis aged } 62)\end{array}$ \\
\hline $\begin{array}{l}\text { Reaching the } \\
\text { organisation }\end{array}$ & $\begin{array}{l}\text { 'Worries about how much it costs and how far to travel' }(0798, \text { male with arthritis aged } 55) \\
\text { 'I don't have a car, I rely on public transport, it's expensive to get around by taxi' }(0179, \text { female with } \\
\text { osteoporosis aged } 82) \\
\text { 'I don't really know about the organisations and no one has recommended me to one' }(0464, \text { female } \\
\text { with chronic kidney disease aged 52) } \\
\text { 'I don't think there would be a health organisation that could help me with my health condition' (0042, } \\
\text { female with asthma aged 56) }\end{array}$ \\
\hline
\end{tabular}

$\mathrm{CHO}=$ consumer health organisation.

participants. Time, cost and transport were explicitly mentioned. Other responses conveyed limited awareness of the existence of CHOs and what they might offer. In direct contrast to the major theme above, three respondents stated they were too unwell to contact a $\mathrm{CHO}$.

\section{Discussion}

Our findings confirm that a minority of general practice patients with diagnosed chronic disease are likely to make contact with a $\mathrm{CHO}$ and they are likely to differ from those who do not make contact in a number of ways. People with diabetes were a striking 27 times more likely to have contacted a $\mathrm{CHO}$ than those with other conditions, whereas patients with higher levels of health care use or poorer self-reported health were three times more likely to have had contact.

The view that 'my doctor does it all' was strongly held among study participants. Being advised to contact a $\mathrm{CHO}$ by their doctor did not retain significance in its own right, suggesting patients with diabetes, more health service contacts and poorer health are more likely to be referred. Our findings underline the vital role of the doctor in

Primary Health Care Research \& Development 2016; 17: 393-404 facilitating contact. Highly consistent across the quantitative and qualitative responses was the view among participants that their health problems were not serious enough to warrant $\mathrm{CHO}$ contact. Difficulties reaching an organisation were raised as secondary barriers and generally reflected a limited awareness of $\mathrm{CHOs}$ and their role.

CHOs are a long-standing tradition in the health care landscape and, while many $\mathrm{CHOs}$ exist (Baggott and Jones, 2014), our findings concur with studies that suggest their ability to reach patients with chronic disease is limited (Ellins and Coulter, 2005; Gucciardi et al., 2006). Levesque et al. (2013) conceptualise access on a broad continuum from the perception of needing care through to the benefits of receiving care. In our study, the primary barriers to $\mathrm{CHO}$ contact reflected attitudinal and system-level factors corresponding to earlier points on that access continuum, specifically: approachability (information provision about the service, and the availability of the service beyond face-to-face contact) and acceptability ('suitability for my stage of the condition'). It may be that other dimensions of access could become more important, if patients had increased access to CHOs earlier in the continuum. 
Other studies have shown a doctor's recommendation to be an important determinant of whether patients act on health information including the use of community-based services (Graziani et al., 1999; Jordan et al., 2008; Mahomed et al., 2008; Beesley et al., 2009; Boyle et al., 2009; Sav et al., 2014). Our study contextualises this finding in relation to $\mathrm{CHOs}$ by showing the extent to which patients rely on the doctor both to recommend and legitimise $\mathrm{CHO}$ contact. The prevailing view that 'the doctor does it all' suggests many patients are unlikely to seek support beyond the confines of the clinic without confirmation from the doctor that further support was warranted and would be of benefit. This strong reliance on the doctor is at odds with the emphasis on patient empowerment, shared decision-making and development of self-management skills that feature heavily in new approaches to chronic illness care and with the realities of the clinical environment where time and other pressures limit opportunities for the delivery of patient education and psychosocial support (Bodenheimer et al., 2002; Oldroyd et al., 2003; Eaton et al., 2015). Yet, the ways in which patients use health services and relate to health professionals are strongly embedded in patterns developed over extended periods of time with strategies for accessing and using services adapted and established as a routine part of everyday life with a chronic condition (Gately et al., 2007). Much heterogeneity also exists in terms of the extent to which both patients and their clinicians embrace shared decision-making (Hoffmann et al., 2014). The perception of CHOs as 'a last resort' indicates a lack of awareness of their contributions to health promotion and health maintenance. Together with the belief that one must be 'sick enough' to seek additional support services, it also highlights challenges associated with the transition from acute to chronic models of care and a shift in emphasis from reactive to proactive care.

Issues such as cost or transport, while often identified as impediments to access (Graziani et al., 1999; Mahomed et al., 2008; Levesque et al., 2013), did not appear as primary barriers. Although some participants referred to cost and transport in openended responses, the view that $\mathrm{CHOs}$ equate to attendance in a physical space suggests many may be unaware of the range and flexibility of support options.
Challenges of engagement exist between $\mathrm{CHOs}$ and the formal health system (Jordan et al., 2008; Morris et al., 2015; Sav et al., 2014). In our study, the very high $\mathrm{CHO}$ contact among those with diabetes shows the critical value of formal linkages between the two sectors. Referral to the peak diabetes CHO (Diabetes Australia) is an accepted part of standard diabetes care (Young et al., 2010) as the $\mathrm{CHO}$ is responsible for the administration of the National Diabetes Services Scheme established by the Australian Government to provide subsidised services and products (such as insulininjecting devices and glucose monitors) (AIHW, 2006). Accordingly, Diabetes Australia is a CHO that has become highly visible and integrated with the health system leading many GPs to see 'definite advantages'of referral (Young et al., 2010). For patients there is a financial driver in the form of subsidised products as well as other potential benefits of contact.

Improving access to $\mathrm{CHOs}$ calls for action at patient, health care provider, $\mathrm{CHO}$ and system levels. Developing referral pathways from primary care to CHOs would help promote access by building awareness and legitimising contact for patients rather than relying on ad hoc self-referral. Structured practice-based approaches to direct patients to $\mathrm{CHOs}$ include social prescribing, patient navigator or linking schemes (Mossabir et al., 2015) and lower-intensity interventions, such as printed referral materials (Boyle et al., 2011). Health system-driven approaches that facilitate the development of formal linkages between CHOs and GPs, as in the case of Diabetes Australia, are clearly beneficial for improving referral pathways. Critical to successful linkages are demonstrable benefits for patients, GP confidence in the organisation and its reputation (Young et al., 2010). Promoting greater understanding of the role and contributions of CHOs could be achieved through greater prominence in clinical practice guidelines and professional training. CHOs also need to ensure their messages are conveyed clearly to health professionals and the public to avoid misperceptions.

A strength of our study is the inclusion of a relatively large consecutive sample of general practice patients. However, caution needs to be exercised in generalising the findings. Our sample is restricted to patients recruited from 18 GPs over a short period of time and includes only participants 
who could speak English well enough to complete a telephone interview. Other minority groups, including Indigenous Australians, are under-represented. Response rates also need to be considered. Although respondents and non-respondents did not differ on key sociodemographic variables, it is not possible to know whether they differed in other ways. Although the research team worked closely with the GPs throughout the recruitment period, responsibility for recruitment was relinquished to the GPs and it is possible that some eligible patients with unknown characteristics were missed for unknown reasons. It is also important to note that this study draws on the baseline phase of a randomised controlled trial designed to evaluate whether an information package would increase $\mathrm{CHO}$ use. Sample bias may have been introduced if participants who were willing to commit to a trial and the two scheduled follow-ups it entailed shared particular characteristics that distinguished them from non-participants, such as a higher level of motivation to seek community support. Whether a one-off survey may have produced different results is uncertain.

Our measure of $\mathrm{CHO}$ contact is a blunt singleitem question with unconfirmed reliability. Further information is not available on the outcomes, nature or patterns of that contact (eg, frequency, timing, recency of contact). All data collected was by self-report and therefore subject to reporting error, including social desirability. The crosssectional survey design is another limitation of the study and directionality of associations between variables cannot be established. Despite these limitations, the study combines quantitative and qualitative data for a detailed account of patients' views of CHOs and influences on $\mathrm{CHO}$ reach. Analysis of free-text responses to a question inviting participants to nominate barriers extends and contextualises our findings. To our knowledge, it is the first study to systematically investigate barriers to $\mathrm{CHO}$ contact in a large and broadly representative group of general practice patients.

Further research to refine and evaluate the outcomes of efforts to improve $\mathrm{CHO}$ access is warranted. More needs to be discovered about the most effective and appropriate ways to improve integration of $\mathrm{CHOs}$ with the formal health system, acknowledging that these may vary greatly given the wide diversity of organisations that exist. Case studies of effective models of integration would enhance understanding of features of success. Longitudinal data on patterns of CHO participation and their outcomes are needed. Little is known about what happens after initial $\mathrm{CHO}$ contact and who benefits from what type of contact. Incorporating outcomes from GP, CHO and patient perspectives would help guide a comprehensive research and policy agenda. While our study is focussed on the Australian setting, rapidly increasing rates of chronic conditions globally call for collaboration across health professionals and the community. The international literature highlights growing recognition of the potential role for CHOs (Baggott and Jones, 2014) and peer support initiatives (Fisher et al., 2014) alongside limited connections between formal professional care and CHOs (Mossabir et al., 2015).

\section{Conclusion}

CHOs are recognised as part of a comprehensive multi-strategy approach to chronic disease selfmanagement, but a disconnect exists between patients and available support services. Our findings indicate there are missed opportunities for CHOs to support health promotion and maintenance for people earlier in the trajectory of chronic illness. A key challenge is better engagement between CHOs and the formal health system that is underpinned by accurate information about how CHOs can contribute.

\section{Acknowledgements}

The authors thank all survey participants and the GPs who assisted with their recruitment for their time and willingness to be part of the study.

\section{Financial Support}

The research reported in this paper is a project of the Australian Primary Health Care Research Institute, which was supported by a grant from the Australian Government Department of Health and Ageing. The information and opinions contained in it do not necessarily reflect the views or policy of the Australian Primary Health Care Research Institute or the Australian Government Department of Health and Ageing. 


\section{Conflicts of Interest}

None.

\section{Ethical Standards}

The study was approved by The University of Queensland's Behavioural and Social Sciences Ethical Review Committee. The authors assert that all procedures contributing to this work comply with the Guidelines of the ethical review process of The University of Queensland and the National Statement on Ethical Conduct in Human Research.

\section{References}

Australian Institute of Health and Welfare (AIHW). 2006: Australia's health 2006. Canberra: AIHW.

Australian Institute of Health and Welfare (AIHW). 2014: Australia's health 2014. Australia's health series no. 14. Cat. no. AUS 178 Canberra: AIHW.

Baggott, R. and Jones, K. 2014: The voluntary sector and health policy: the role of national level health consumer and patients' organisations in the UK. Social Science \& Medicine 123, 202-9.

Beesley, V.L., Janda, M., Eakin, E.G., Auster, J.F., Chambers, S.K., Aitken, J.F., Dunn, J. and Battistutta, D. 2009: Gynecological cancer survivors and community support services: referral, awareness, utilisation and satisfaction. Psycho-Oncology 19, 54-61.

Blakeman, T., Blickem, C., Kennedy, A., Reeves, D., Bower, P., Gaffney, H., Gardner, C., Lee, V., Jariwala, P., Dawon, S., Mossabir, R., Brooks, H., Richardson, G., Spackman, E., Vassilev, I., Chew-Graham, C. and Rogers, A. 2014: Effect of information and telephone-guided access to community support for people with chronic kidney disease: randomised controlled trial. PLoS One 9, e109135.

Bodenheimer, T., Lorig, K.R., Holman, H. and Grumbach, K. 2002: Patient self-management of chronic disease in primary care. The Journal of the American Medical Association 288, 2469-75.

Boyle, F., Mutch, A., Dean, J., Dick, M.L. and Del Mar, C.B. 2009: Consumer health organisations for people with diabetes and arthritis: who contacts them and why? Health \& Social Care in the Community 17, 628-35.

Boyle, F., Mutch, A., Dean, J., Dick, M.L. and Del Mar, C.B. 2011: Increasing access to consumer health organisations among patients with chronic disease: a randomised trial of a print-based intervention. Primary Health Care Research \& Development 12, 245-54.

Braun, V. and Clarke, V. 2006: Using thematic analysis in psychology. Qualitative Research in Psychology 3, 77-101.
Busija, L., Pausenberger, E., Haines, T., Haymes, S., Buchbinder, R. and Osborne, R. 2011: Adult measures of general health and health-related quality of life. Arthritis Care \& Research 63 (Suppl 11), s383-412.

Department of Health and Ageing, Commonwealth Government of Australia. 2013: National primary health care strategic framework. Retrieved 1 May 2015 from www. health.gov.au/internet/publications/publishing.nsf/Content/ NPHC-Strategic-Framework

De Vaus, D. 2002. Surveys in social research. St Leonards, NSW: Allen \& Unwin.

Eaton, S., Roberts, S. and Turner, T. 2015: Delivering person centred care in long term conditions. British Medical Journal 350, h181.

Ellins, J. and Coulter, A. 2005. How engaged are people in their health care? Findings of a national telephone survey. Oxford: Picker Institute Europe.

Epping Jordan, J.E., Pruitt, S.D., Bengoa, R. and Wagner, E.H. 2004: Improving the quality of health care for chronic conditions. Quality and Safety in Health Care 13, 299-305.

Fisher, E.B., Coufal, M.M., Parada, H., Robinette, J.B., Tang, P.Y., Urlaub, D.M., Castillo, C., Guzman-Corrales, L.M., Hino, S., Hunter, J., Katz, A.W., Symes, Y.R., Worley, H.P. and Xu, C. 2014: Peer support in health care and prevention: cultural, organizational, and dissemination issues. Annual Review of Public Health 35, 363-83.

Gately, C., Rogers, A. and Sanders, C. 2007: Re-thinking the relationship between long-term condition self-management education and the utilisation of health services. Social Science \& Medicine 65, 934-45.

Grant, C., Goodenough, T., Harvey, I. and Hine, C. 2000: A randomised controlled trial and economic evaluation of a referrals facilitator between primary care and the voluntary sector. British Medical Journal 320, 419-23.

Graziani, C., Rosenthal, M.P. and Diamond, J.J. 1999: Diabetes education program use and patient-perceived barriers to attendance. Family Medicine 31, 358-63.

Gucciardi, E., Smith, P.L. and Demelo, M. 2006: Use of diabetes resources in adults attending a self-management education program. Patient Education and Counseling 64, 322-30.

Hoffmann, T.C., Légaré, F., Simmons, M.B., McNamara, K., McCaffery, K., Trevena, L.J., Hudson, B., Glasziou, P. and Del Mar, C.B. 2014: Shared decision making: what do clinicians need to know and why should they bother? Medical Journal of Australia 201, 35-39.

Jordan, J.E., Briggs, A.M., Brand, C.A. and Osborne, R.H. 2008: Enhancing patient engagement in chronic disease selfmanagement support initiatives in Australia: the need for an integrated approach. Medical Journal of Australia 189, S9-13.

Kurtz, L.F. 1997. Self-help and support groups: a handbook for practitioners. Thousand Oaks, CA: Sage.

Kyrouz, E., Humphreys, K. and Loomis, C. 2002: A review of research on the effectiveness of self-help mutual aid groups. In White, B.J. and Madara, E.J., editors American self-help clearinghouse self-help group sourcebook, seventh edition. 
Cedar Knolls, NJ: American Self-Help Group Clearinghouse, 71-85.

Levesque, J.-F., Harris, M.F. and Russell, G. 2013: Patientcentred access to health care: conceptualising access at the interface of health systems and populations. International Journal of Equity in Health 12, 18.

Mahomed, R., Patterson, E. and St John, W. 2008: Factors influencing possible participation in chronic disease selfmanagement courses. Australian Journal of Primary Health 14, 19-26.

Morris, R., Kirk, S., Kennedy, A., Vassilev, I., Mathieson, A., Jeffries, M., Blickem, C., Brooks, H., Sanders, C. and Rogers, A. 2015: Connecting local support: a qualitative study exploring the role of voluntary organisations in long-term condition management. Chronic Illness 11, 140-55.

Mossabir, R., Morris, R., Kennedy, A., Blickem, C. and Rogers, A. 2015: A scoping review to understand the effectiveness of linking schemes from healthcare providers to community resources to improve the health and well-being of people with long-term conditions. Health \& Social Care in the Community 23, 467-84.

Oldroyd, J., Proudfoot, J., Infante, F.A., Powell Davies, G., Harris, M.F., Bubner, T., Holton, C. and Beilby, J. 2003: Providing healthcare for people with chronic illness: the views of Australian GPs. Medical Journal of Australia 179, 30-33.

Sav, A., McMillan, S.S., Kelly, F., Whitty, J.A., Kendall, E., King, M.A. and Wheeler, A.J. 2014: Consumer health organisations for chronic conditions: why do some people access them and others don't? Primary Health Care Research \& Development 15, 418-29.

SPSS. 2006: SPSS for Windows, Rel 15.0.0. Chicago, IL: SPSS, Inc. Ware, J.E., Kosinski, M., Turner-Bowker, D.M. and Gandek, B. 2005: How to score Version 2 of the SF-12 health survey. Lincoln, RI: Quality Metric Incorporated.

Young, C.E., Mutch, A.J., Boyle, F.M. and Dean, J.H. 2010: Investigating referral pathways from primary care to consumer health organisations. Australian Journal of Primary Health 16, 260-67. 